\title{
Erratum to: Safety and tolerability of AZD8055 in Japanese patients with advanced solid tumors; a dose-finding phase I study
}

\author{
Hajime Asahina $\cdot$ Hiroshi Nokihara • \\ Noboru Yamamoto • Yasuhide Yamada • \\ Yosuke Tamura • Kazunori Honda • Yoshitaka Seki • \\ Yuko Tanabe • Hitoshi Shimada • Xiaojin Shi • \\ Tomohide Tamura
}

Published online: 5 September 2012

(C) Springer Science+Business Media, LLC 2012

\section{Erratum to: Invest New Drugs}

\section{DOI 10.1007/s10637-012-9860-4}

An error occurred in processing the original article: Figure $1 \mathrm{~b}$ was reproduced in place of Figure 1a. The correct Figure 1 is shown below.

The online version of the original article can be found at http:// dx.doi.org/10.1007/s10637-012-9860-4.

H. Asahina $\cdot$ H. Nokihara $\cdot$ N. Yamamoto $\cdot$ Y. Tamura $\cdot$

K. Honda $\cdot$ Y. Seki $\cdot$ Y. Tanabe $\cdot$ T. Tamura $(\triangle)$

Division of Internal Medicine and Thoracic Oncology,

National Cancer Center Hospital,

Tsukiji 5-1-1, Chuo-ku,

Tokyo 104-0045, Japan

e-mail: ttamura@ncc.go.jp

\section{Y. Yamada}

Division of Gastrointestinal Oncology,

National Cancer Center Hospital,

Tokyo, Japan

H. Shimada $\cdot$ X. Shi

Research and Development, AstraZeneca KK,

Osaka, Japan
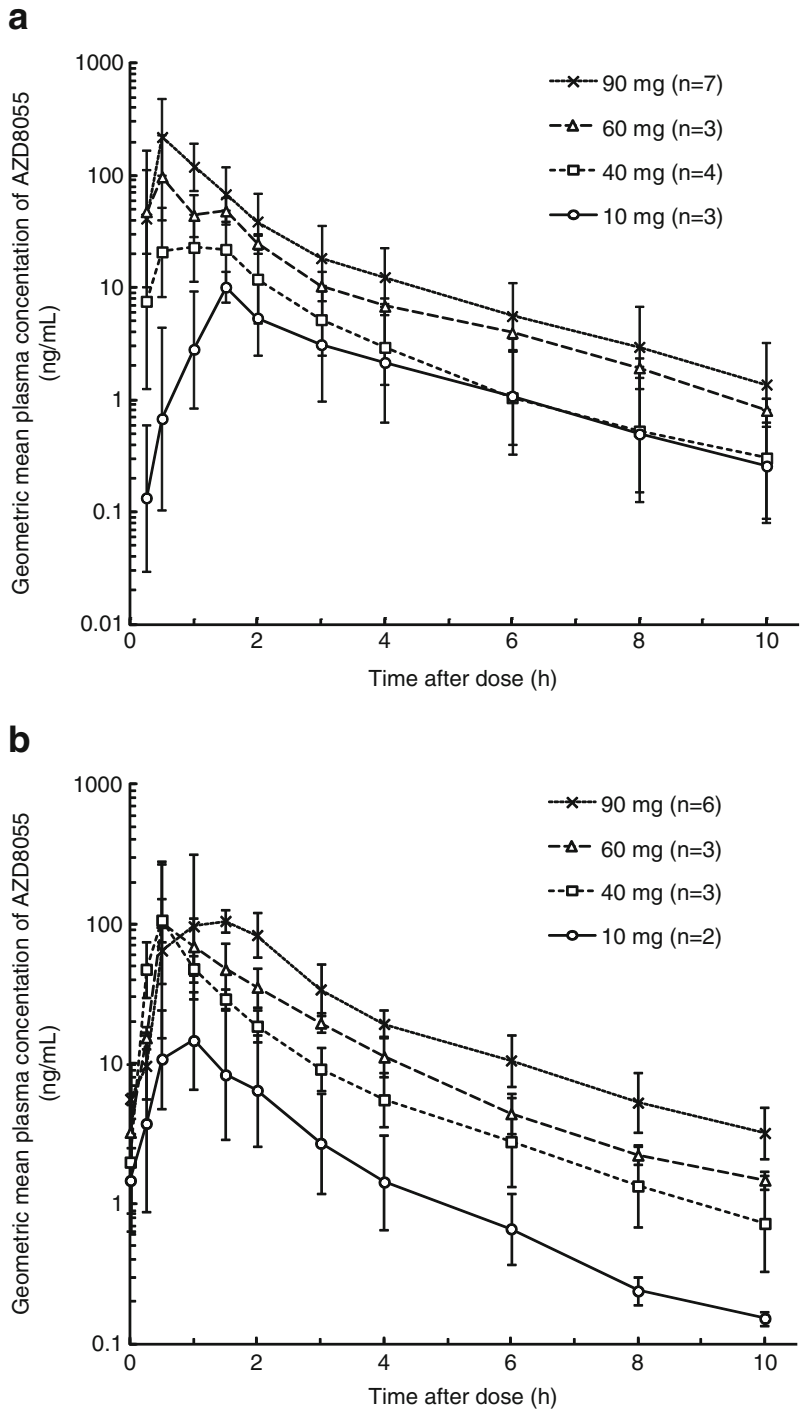

Fig. 1 Geometric mean plasma concentrations of AZD8055 versus time following a single dose (a) and at steady state (b) 